\title{
Amamentação e prática de benzimentos: revisão integrativa.
}

\section{Breastfeeding and practice healers: integrative review.}

\section{La lactancia materna y lapráctica benzimentos: revisión integradora.}

SuzelaineTaizeSTADLER ${ }^{1}$

Cristina Ide FUJINAGA ${ }^{2}$

RESUMO: Objetivo: investigar a prática de benzimentos relacionados ao processo de amamentação. Métodos: Trata-se de uma revisão integrativa, com publicações coletadas no banco de dados: ScientificElectronic Library Online (SciELO); Google Scholar e ResearchGate, resultando em duas publicações para a amostra. Resultados: Os estudos abordam a prática de benzedeiras como uma forma alternativa de tratamento eficaz para ser utilizado durante a lactação; a busca pela prática de benzedeiras ocorre pelas próprias mulheres geralmente logo após o nascimento do bebê, por influências familiares, pelos amigos e também pelo ambiente social. Conclusão: Observou-se que a utilização da prática de benzimentos são eficazes frente as dificuldades que podem surgir durante o processo de amamentação. Além disso, percebe-se que a postura das benzedeiras é de acolhimento e as mesmas fazem parte da rede social das mulheres. Diante disso, torna-se relevante que os profissionais de saúde reconheçam a importância das relações da rede social das mulheres que amamentam e valorizem os aspectos culturais e saberes populares constituintes do processo de amamentação.

Palavras Chave: amamentação, cultura, medicina popular.

ABSTRACT: Objective: To investigate the practice of benzimentos related to breastfeeding. Methods: This is an integrative review, with publications collected in the database: Scientific Electronic Library Online (SciELO); Google Scholar and ResearchGate, resulting in two publications for the sample. Results: The studies address the practice of healers as an alternative form of effective treatment for use during lactation; the search for practice faith healing occurs by women themselves usually after the baby's birth, by family influences, friends and also by

\footnotetext{
1 Universidade Estadual do Centro-Oeste - UNICENTRO. Departamento de Fonoaudiologia. Programa de PósGraduação Interdisciplinar em Desenvolvimento Comunitário. E-mail: fonoaudiologasuzelaine@hotmail.com 2 Universidade Estadual do Centro-Oeste - UNICENTRO. Departamento de Fonoaudiologia. Programa de PósGraduação Interdisciplinar em Desenvolvimento Comunitário. E-mail: cifujinaga@gmail.com
} 
the social environment. Conclusion: It was observed that the use of healers practice are effective across the difficulties that may arise during the breastfeeding process. In addition, it is clear that the approach of healers is the host and the same part of the social network of women. Therefore, it is important that health professionals recognize the importance of the relationship of social network of breastfeeding women and enhance the cultural aspects and popular knowledge constituents of breastfeeding.

Keywords: Breastfeeding, Culture, The folk medicine.

RESUMEN: Objetivo: Investigar lapráctica de benzimentos relacionados conlalactanciamaterna. Métodos: Se trata de una revisión integradora, conpublicacionesrecogidasenla base de datos: ScientificElectronic Library Online (SciELO); Google Scholar y ResearchGate, dando lugar a dos publicaciones de lamuestra. Resultados: Los estudiosabordanlapráctica de loscuranderos como una forma alternativa de tratamiento eficaz para su uso durante lalactancia; labúsqueda de lacuraciónpráctica de fe se produce por laspropiasmujeres por lo general despuésdelnacimientodel bebé, por influencias familiares, amigos y también por el entorno social. Conclusión: Se observó que el uso de lapráctica de loscuranderossoneficaces a través de lasdificultades que puedan surgir durante elproceso de lalactancia materna. Además, es evidente que el enfoque de los curadores es elanfitrión y lamisma parte de lared social de lasmujeres. Por lo tanto, es importante que losprofesionales de lasaludreconocenlaimportancia de larelación de lared social de lasmujeres que amamantan y mejorarlos aspectos culturales y constituyentesconocimientos populares de lalactancia materna.

Palabras Clave:Amamantamiento, Cultura, La medicina popular.

\section{INTRODUÇÃO}

A amamentação é uma prática que sofreu mudanças ao longo do tempo e está vinculada a diversos aspectos. Na literatura científica, a amamentação está principalmente relacionada aos aspectos biológicos e orgânicos, além dos psicológicos; os aspectos sociais e culturais são menos abordados $^{1}$. Especificamente, com relação aos fatores culturais, se destacam as crenças e saberes populares $^{2}$. No presente artigo, pretende-se particularizar as práticas de benzimentos.

A prática de benzimentos normalmente é desenvolvida por mulheres, denominadas benzedeiras. O benzimento ou a benzeção envolve a cura de males a partir da reza, da oração, de ramos verdes naturais, de rituais, de simpatias, entre outros ${ }^{3}$.

Os valores e as crenças atribuídas às práticas de benzedeiras são comumente transmitidos de geração em geração ${ }^{4}$, e envolvem questões ligadas à fé, a religião e a espiritualidade 5 .

Em relação à amamentação, o benzimento é considerado como uma fonte de apoio perante as dificuldades encontradas neste processo. Além disso, as benzedeiras simbolizam uma proteção e 


\section{$213 / /$}

até a cura na presença de alguma alteração tanto do bebê quanto da mãe ${ }^{6}$. Segundo Lana ${ }^{7}$, a maioria das mulheres apresenta dificuldades e necessitam de ajuda ou de auxílio para amamentar. Perante essas situações, justifica-se o fato delas procurarem auxílio/ajuda com benzedeiras.

Dentre os motivos que levam as mães a utilizarem a prática de benzimentos destaca-se as iatrogenias e os altos custos da medicina ${ }^{8}$. Ainda, destaca-se que o uso de práticas populares das benzedeiras surge perante a insatisfação das mulheres com a medicina tradicional ou de uma possível cura das disfunções do corpo9.

Reconhecendo que o processo do aleitamento materno é um ato complexo e imbricado de subjetividade, que envolve aspectos culturais e saberes populares, o objetivo do presente estudo é investigar a prática de benzimentos relacionados ao processo de amamentação.

\section{MÉTODOS}

Este estudo é uma revisão integrativa, composta por um percurso metodológico de leitura exploratória e de seleção de materiais, de modo considerado sistemático e ordenado, para contribuir para o conhecimento da temática analisada ${ }^{10}$. Para elaborar este estudo, a primeira etapa foi definir o tema e a questão norteadora, que neste estudo foi "qual a relação entre as práticas de benzimento e o processo de amamentação?”. Na segunda etapa, definiu-se os critérios de exclusão e inclusão, a saber, critérios de inclusão as publicações de periódicos científicos, no idioma português, espanhol e inglês, com ano de publicação de 2000 a 2015, que apresentaram a prática de benzimentos durante o processo de amamentação. Foram excluídos artigos com anos de publicação inferior ao ano 2000, estudos de revisão e duplicados. O período da coleta de dados foi o mês de novembro de 2015. Na terceira etapa definiu-se os dados e a caracterização dos estudos, sendo busca de publicações nas bases de dados ScientificElectronic Library Online (SciELO); Google Acadêmico e no Researchgate, utilizando a combinação dos descritores: amamentação; aleitamento materno, benzedeiras e benzimentos e seus correspondentes na versão inglesa. As duas últimas etapas, quarta e quinta etapas, interpretação dos resultados e apresentação da revisão, serão apresentadas a seguir ${ }^{11}$.

Ao todo foram encontrados 306 estudos. Entretanto, após uma minuciosa leitura foram selecionadas dois artigos que atendiam o objetivo deste estudo e também os critérios de inclusão e que, portanto, compuseram a amostra desta pesquisa.

Cabe salientar que a amostra selecionada está referenciada ao final do estudo, respeitando e identificando os seus autores, assim como todas as fontes de pesquisa. Além disso, foram rigorosamente respeitados os aspectos éticos da propriedade intelectual das publicações, no que se refere ao uso do conteúdo e nas citações das obras da amostra.

\section{RESULTADOS}

A amostra deste estudo foi composta por duas publicações, oriundas de diversas áreas de 


\section{$214 / /$}

conhecimento em ciências da saúde. A partir do objetivo deste estudo, identificou-se que os trabalhos selecionados buscaram investigar a utilização das práticas de benzimentos durante o processo de amamentação. Os dados coletados estão descritos a seguir.

O artigo A1 é intitulado como "Práticas populares nas mães adolescentes nos seis primeiros meses de vida", e teve por objetivo de identificar e descrever os cuidados populares adotados por mães adolescentes nos seis primeiros meses de vida. Os resultados apontaram que as mães procuram benzedeiras diante de intercorrências inesperadas. Em A1 a busca pela prática de benzimento ocorreu a partir de uma orientação médica de complementação láctea específica. Conforme o artigo, um profissional de saúde insinuou que a mãe por ter os peitos "murchos" não tinha leite suficiente para alimentar o bebê. Diante deste evento a mãe procurou a benzedeira buscando prevenir algum problema de saúde e também buscando proteção ao bebê.

Ao pensar que os "peitos murchos" podem significar ter "pouco leite", a mãe pode passar a ter sentimentos de insegurança e ter abalada a sua autoestima, desestimulando a amamentação. A origem deste mito pode ter ocorrido pelo fato de que, quando o bebê nasce, é comum a mãe ficar com os peitos cheios nos primeiros dias, pois o corpo ainda não sabe quanto leite precisa produzir para a demanda do bebê. Tal fenômeno acarreta numa produção láctea maior do que o bebê necessita naquele momento, dando a sensação de "peito cheio". Porém após essas primeiras semanas, a regulação do volume de produção láctea passa a depender da demanda, sendo diretamente proporcional ao número de mamadas ${ }^{12}$. Ou seja, a própria sucção do bebê irá determinar a produção do leite. Consequentemente, os peitos não irão ficar "cheios" o tempo todo, sem que isso signifique que o peito da mãe tenha pouco leite ${ }^{13}$.

Entretanto, no artigo de A1 a orientação equívoca do profissional diz respeito ao desconhecimento do manejo clínico da amamentação, pois se ele tivesse compreensão da anatomia e da fisiologia da lactação certamente não teria dado esta orientação à mãe. Vale ressaltar que o manejo da amamentação também envolve ações e cuidados para o estabelecimento e manutenção do aleitamento materno, orientação quanto à produção láctea e também do tratamento e prevenções de possíveis problemas ${ }^{14}$. Deve-se lembrar que somente considerar o conjunto e a indicação de normas técnicas não garante o sucesso da amamentação, ou seja, além disso deve-se levar em conta as diferenças individuais das mulheres e de seus filhos ${ }^{15}$.

O artigo de A2 é intitulado como Práticas utilizadas por puérperas nos problemas mamários, e teve por objetivo conhecer as práticas do cuidado das puérperas relacionadas aos problemas mamários e intervir na resolução do problema em nível domiciliar. Os resultados demonstraram que as puérperas procuram as benzedeiras perante dificuldades com fissuras. E para tratamento das fissuras as benzedeiras utilizaram arruda (respingos, infusão de ervas e ramalhete).

Entretanto, apesar do artigo fortalecer os estudos científicos que trazem as crenças e culturas da prática de benzimento e também retratar a utilização benéfica do uso de chás/ervas medicinais, ele 
apresenta o saber popular de uma forma hierárquica em relação ao saber científico, pois expõe uma reflexão de que apesar do saber popular sobre o uso de chás medicinais proporcionarem benefícios e confortos as mães que aderem, a utilização dessas práticas deve ser realizada de forma prudente, de maneira que não ocasione complicações às mulheres que fazem uso dessas práticas populares.

Porém, à medida que se legitima o saber científico desvalorizando o saber popular, desconstrói o conhecimento comum de forma que a ciência torna-se a única forma capaz de oferecer soluções as necessidades humanas ${ }^{16}$. Essa forma da ciência entender que a solução dos males está na medicalização e na comprovação científica corresponde ao entendimento de muitos profissionais de saúde ${ }^{17}$. Entretanto, especialmente nos fenômenos saúde/doença, o conhecimento científico atua paralelamente com o conhecimento popular, principalmente pelo fato de ser impossível separar as noções e práticas de saúde da cultura dos indivíduos, sobretudo a atuação das benzedeiras cujas práticas são milenares ${ }^{18}$.

\section{DISCUSSÃO}

É possível identificar nos trabalhos a utilização da benzeção como um recurso terapêutico que auxilia na cura ou na ajuda da resolução de problemas encontrados durante o processo de aleitamento materno ${ }^{19}$. A literatura mostra que muitas mães apresentam dificuldades quanto à amamentação de seus filhos ${ }^{7,20,21}$. Diante disso, torna-se relevante refletir sobre a importância da atuação à amamentação. Todos os atores envolvidos nesse processo devem buscar auxiliar e apoiar as mães, para que elas possam se sentir acolhidas e seguras a fim de superar possíveis dificuldades decorrentes do processo de aleitar ${ }^{22,23}$, dando escuta e atenção as suas necessidades ${ }^{24}$, do mesmo modo que elas encontram quando buscam terapias alternativas.

Com especial atenção à saúde, as mulheres estão subordinadas as políticas públicas atuais, tais como a Iniciativa Hospital Amigo da Criança. Essa política procura promover, proteger, apoiar e aumentar a prevalência da amamentação ${ }^{25}$. Entretanto, chama a atenção o fato desta política lidar com a amamentação como uma obrigação da nutriz. Desta forma, pode-se inferir que a busca pelas benzedeiras seja um recurso alternativo de ajuda exercido pelas mães, na tentativa de sanar seus anseios e dificuldades com alguém que não ocupe um lugar de julgamento ou culpabilidade. Notase que, muitas vezes, são essas as atitudes exercidas pelos profissionais de saúde.

Outro fato relevante é a procura por benzedeiras diante de algumas crenças, como por exemplo, a de que não tem leite suficiente ${ }^{26}$. Podemos inferir, no entanto, que a benzedeira pode perceber outras questões que estão por trás da indicação do complemento. Entende-se que quando as mães procuraram a benzedeira com a queixa de "pouco leite ou leite fraco" pode ser que esta queixa tenha relação com alguma dificuldade no manejo da amamentação. A pega incorreta limita o esvaziamento completo das mamas que ocasionará uma diminuição na síntese da produção láctea, pela inibição mecânica e química ${ }^{27}$. Tal comportamento pode ser percebido de forma errônea pela mãe, fazendo com que ela se sinta com uma produção láctea ineficiente. Consequentemente, o bebê 
poderá sofrer perda de peso e desidratação, esta última visualmente percebida pela benzedeira. Daí a conduta dela de complementar o bebê.

Observaram-se ainda nos estudos que as benzedeiras têm alguma relação com quem a procura, seja com os familiares, com os amigos ou com a própria puérpera ${ }^{28}$. Além disso, são vistas com poderes especiais que, a partir da reza e da oração, protege os bebês e dão suporte nas práticas de $\operatorname{amamentar}^{29}$. No contexto da amamentação, a nutriz é influenciada pela sua rede social e de apoio, recebendo incentivo ou não para amamentar ${ }^{30}$. Os principais atores dessa rede são os familiares, especialmente o pai e as avós ${ }^{31}$. As práticas atribuídas na literatura ao papel do pai consistem na assistência em dar atenção à mãe, englobando ações de afeto e de carinho tanto para ela quanto para o beb $\hat{e}^{31}$. Envolve ainda manter-se próximo a nutriz fazendo companhia durante as mamadas, incentivando positivamente a amamentação ${ }^{32}$. Já as práticas relacionadas às avós configuram-se extremamente importantes para a manutenção da amamentação. São vistas principalmente quanto ao apoio e o aconselhamento prático devido as suas experiências ${ }^{33}$. Portanto, todos que compõe a rede social da mulher são importantes mantenedores da amamentação. Essa rede representa para a mulher acolhimento, auxílio perante as dificuldades, apoio verbal, fazendo com que a nutriz compartilhe este momento ${ }^{4}$.

Ainda é necessário considerar a tríade que envolve a questão da eficácia dos benzimentos no processo de amamentação: a fórmula da benção, a fé no tratamento ou na cura a partir de um ser divino e a confiança na prática do benzedor ${ }^{34}$. No aspecto cultural do benzimento, corpo e espírito não se separam e para tudo o que afetar o corpo ou a alma terá uma reza para o alívio ou para a sua cura. Por isso, apesar do avanço da medicina e da tecnologia, a prática de benzimentos ainda é fortemente presente ${ }^{34}$. Ainda, vale ressaltar que para a eficácia do benzimento é necessária a crença na base metafísica dos fenômenos.

Diante deste contexto, entendemos que a crença no benzimento exerce um papel singular no período do aleitamento materno, especialmente pelo fato do sistema de crenças determinar uma "certa" explicação e tratamento para os fenômenos incompreendidos ou que ainda não tem uma resposta científica comprovada ${ }^{35}$. Assim, a prática de benzimentos interfere no processo de amamentação, sobretudo por esta fase de aleitar apresentar momentos de fragilização e cuidados com a saúde.

\section{CONCLUSÃO}

A partir deste estudo destaca-se a necessidade das mães em buscar auxílio junto às benzedeiras, para melhorar a sua saúde ou livrar-se de dificuldades. Esse fato pode ser justificado pelo papel do benzimento junto a dificuldades encontradas durante o processo de amamentação. Nos artigos apresentados, as práticas das benzedeiras representaram um apoio e uma resolução diante das queixas das mulheres que amamentam. Ainda, percebe-se que a postura das benzedeiras é de acolhimento e as mesmas fazem parte da rede social das mulheres, sendo despidas de atitudes de julgamento ou 
de culpabilidade.

Cabe aos profissionais de saúde, que assistem a dupla mãe-bebê e participam do processo inicial do aleitamento materno,reconhecer a importância das relações da rede social das mulheres que amamentam e valorizar os aspectos culturais e saberes populares constituintes do processo de amamentação.

\section{REFERÊNCIAS BIBLIOGRÁFICAS}

1. ALMEIDA, J.A.G.; NOVAK, F.R. Amamentação: um híbrido natureza-cultura. Journal de Pediatria, Rio de Janeiro, v. 80, n. 5, p.119-125, 2004.

2. MARQUES, E.S.; COTTA, R.M.M.; PRIORI, S.E. Mitos e crenças sobre o aleitamento materno. Ciência \& Saúde Coletiva, v. 16, n. 5, p. 2461-2468, 2011.

3. ANDRADE, C.A.M. O universo das benzedeiras: uma análise ontológica e semiológica da prática ritual e das narrativas de benzedeiras de Rebouças - PR. In V Congresso da ANPTECRE "Religião, Direitos Humanos e Laicidade", 5, 2015, Curitiba. Anais... Curitiba: PUC-PR, 2015.

4.MARQUES, R.F.S.V.; COTTA, R.M.M; MAGALHÃES, K.A.; et al. A influência da rede social da nutriz no aleitamento materno: o papel estratégico dos familiares e dos profissionais de saúde. Ciência \& Saúde Coletiva. v. 15, p. 1391-1400, 2010.

5. MEDEIROS, R.E.G.; NASCIMENTO, E.G.C. do; DINIZ, G.M.D.; et al. Na simplicidade a complexidade de um cuidar: a atuação da benzedeira na atenção à saúde da criança. Physis. v. 23, n. 4, p. 1339-1357, 2013.

6. PRAÇA N.S.; GUALDA D.M.R. Cuidar da saúde da família: responsabilidade da mulher moradora em uma favela. Família Saúde Desenvolvimento. v.2, n. 1, p. 13-20, 2000.

7. LANA, A.P.B. O livro de estímulo a amamentação: uma visão biológica, fisiológica e psicológica comportamental da amamentação. São Paulo: Atheneu, 2001, 423 p.

8. FORTES, J.A.M.S; SANTOS, L.S.; MORAES, S.D.S. Percepção de mães sobre o uso de práticas integrativas e complementares em seus filhos. Enfermagem em Foco. v. 5, n. 2, p. 37 40, 2014.

9. ELIAS, M.C.; ALVES, A.; TUBINO, P. Uso de medicina não convencional em crianças com câncer. Revista Brasileira de Cancerologia , v. 52, n. 3, p.237 - 243, 2006. 
10. MENDES, K.D.S.; SILVEIRA R.C.C.P.; GALVÃO C.M. Revisão integrativa: método de pesquisa para a incorporação de evidências na saúde e na enfermagem. Texto Contexto Enfermagem. v. 17, n. 4,p. 758-764, 2008.

11. ROMAN, A.R.; FRIEDLANDER, M.R. Revisão integrativa de pesquisa aplicada à enfermagem. Cogitare Enfermagem. v.3, n. 2, p. 109-112, 1998.

12. MONTEIRO, J.C.S.; GOMES, F.A.; STEFANELLO, J.; et al . Leite produzido e saciedade da criança na percepção da nutriz durante o aleitamento materno exclusivo. Texto contexto Enfermagem, Florianópolis, v. 20, n. 2, p. 359-367, 2011.

13. JALDIN, M.G.M.; SANTANA, R.B. Anatomia da mama e fisiologia da lactação. In: REGO, J. D. (Org.) Aleitamento materno. São Paulo: Atheneu, 2001, p. 35-46.

14. AZEVEDO, A.R.R., et al. O manejo clínico da amamentação: saberes dos enfermeiros. Escola Anna Nery, Rio de Janeiro, v. 19, n.3, p. 439- 445, 2015.

15. TERUYA, K.; SERVA, V.B. Manejo da lactação. In: In: REGO, J. D. (Org.) Aleitamento materno. São Paulo: Atheneu, 2001, p. 35-46.

16. LOPES, A.R.C. Reflexões sobre currículo: as relações entre senso comum, saber popular e saber escolar. Em Aberto, v. 12, n. 58, p.16, 1993.

17. JUNGES, J.R.; et al. Saberes populares e cientificismo na estratégia saúde da família: complementares ou excludentes? Ciência \& Saúde Coletiva. v.16, n.11, p. 4327-4335, 2011.

18. SANTOS, A.C.B.; SILVA, A.F.; SAMPAIO, D.L.; et al. Antropologia da saúde e da doença: contribuições para a construção de novas práticas em saúde. Revista NUFEN, v.4, n.2, p. 11-21, 2012.

19. ZORZI, N.T.; BONILHAA.L.L. Práticas utilizadas pelas puérperas nos problemas mamários, Revista Brasileira de Enfermagem. v.59, n.4, p. 521-526, 2006.

20. CARVALHAES, M.A.B.L.; CORREA, C.R.H. Identificação de dificuldades no início do aleitamento materno mediante aplicação de protocolo. Journalof Pediatria. v. 79, n. 1, p.13-20, 2003.

21. MARQUES, R.F.S.V.; CUNHA, I.C.C.; ARAGON, M.G.; et al. Fatores relacionados às dificuldades no aleitamento materno entre mães adolescentes da Fundação Santa Casa de Misericórdia do 57-Pará. Revista. Paraense de Medicina,.v. 22, n. 1,p. 57-62, 2008. 
22. ESCARCE, A.G.; ARAÚJO, N.G.; FRICHE, A.A.L.; et al. Influência da orientação sobre aleitamento materno no comportamento das usuárias de um hospital universitário. Revista CEFAC. v.15, n.6, p.1570-1582, 2013.

23. GIUGLIANI, E.R.J. O aleitamento materno na prática clínica. Journal of Pediatria. v. 21, p.238-252, 2000.

24. SOARES, A.V.N.; GAIDZINSKI, R.R.; CIRICO, M.O.V. Identificação das intervenções de enfermagem no Sistema de Alojamento Conjunto. Revista da Escola de Enfermagem da USP, v. 44, n. 2, p. 308-317, 2010.

25. BRASIL. Ministério da Saúde. Iniciativa hospital amigo da criança: revista, atualizada e ampliada para o cuidado integrado. Módulo I - Histórico e implementação. Brasília, DF, 2008, p.77.

26. TOMELERI, K.R.; MARCON, S.S. Práticas populares de mães adolescentes no cuidado aos filhos. Acta Paulista Enfermagem, v. 22, n. 3, p. 272-280, 2009.

27. GIUGLIANI, E.R.J.Problemas comuns na lactação e seu manejo. Journal ofPediatria. v. 80, n.5,p. $147-154,2004$.

28. SILVA, Y.F. Família e redes sociais: o uso das práticas populares no processo saúde e doença. In: SILVA YF, FROENÇO MC. Saúde e doença: uma abordagem cultural da enfermagem. Florianópolis (SC): Papa Livro; 1996. p.75-93.

29. LUZ, A.M.H.; BERNI, N.I.O.; SELLI, L. Mitos e tabus da maternidade: um enfoque sobre o processo saúde-doença. Revista Brasileira Enfermagem. v. 60, n. 1, p. 42-48, 2007.

30. TURNBULL-PLAZA, B.; ESCALANTE-IZETA, E.; KLUNDERKLUNDER, M. The role of social networks in exclusive breastfeeding.Revista Médica del Instituto Mexicano del Seguro Social . v. 44, n. 2, p. 97-104, 2006.

31. SOUSA, A.M.; FRACOLLI, L.A.; ZOBOLI, E.L.C.P. Práticas familiares relacionadas à manutenção da amamentação: revisão da literatura e metassíntese. Revista Panamericana de SaludPublica, v. 34, n. 2, p. 127-134, 2013.

32. BRITO, R.S.;OLIVEIRA, E.M. Aleitamento materno: mudanças ocorridas na vida conjugal do pai. Revista Gaucha Enfermagem. v.27, n.2, p.193-202, 2006. 
33. BARREIRA, S.M.C.; MACHADO, M.F.A.S. Amamentação: compreendendo a influência do familiar. Acta Scientiarum, Health Sciences. v.26, n.1, p.11-20, 2004.

34. NERY, V.C. Rezas, Crenças, Simpatias e Benzeções: costumes e tradições do ritual de cura pela fé. In: Encontro dos Núcleos de Pesquisas da Intercom, 6., 2006, Brasília. Anais... Brasília: UnB, 2006, p. 1-15.

35. STUART, G.W.; LARAIA, M.T. Enfermagem Psiquiátrica, Princípios e Prática. 6 a ed. Porto Alegre: ARTMED, 2001.

Artigo apresentado em 20-10-15

Artigo aprovado em 27-04-16

Artigo publicado no sistema em 30-04-16 